\title{
Validation of the Level 1c and Level 2 SMOS Products with Airborne and Ground-based Observations
}

\author{
$\underline{\text { C. Rüdiger }}^{\text {a }}$, J.P. Walker ${ }^{\text {a }}$, Y.H. Kerr ${ }^{\text {b }}$, A. Mialon ${ }^{\text {b }}$, O. Merlin ${ }^{\text {b }}$ and E.J. Kim ${ }^{\text {c }}$ \\ ${ }^{a}$ Department of Civil Engineering, Monash University, Australia \\ ${ }^{b}$ Biospheric Processes, Centre d'Etudes Spatiales de la Biosphère (Cesbio), CNES, France \\ ${ }^{c}$ Hydrospheric and Biospheric Sciences Laboratory, NASA Goddard Space Flight Center, USA \\ Email: chris.rudiger@monash.edu
}

\begin{abstract}
In the Austral summer and winter periods of 2010, two large field campaigns (the Australian Airborne Cal/val Experiments for SMOS (AACES)) were undertaken for the validation of the Level 1c brightness temperature and Level 2 soil moisture products of the ESA-led Soil Moisture and Ocean Salinity (SMOS) mission, which constitutes the first of a series of future soil moisture satellite missions. SMOS is also the first polar-orbiting satellite operating at a frequency of $1.4 \mathrm{GHz}$ (L-band) and even more importantly is the first 2-dimensional interferometric radiometer used for Earth observation purposes. Consequently, extensive and detailed field campaigns for its product validation are required. The field site of this study lies within the Murrumbidgee River catchment of southern New South Wales, in south-eastern Australia. The advantage of this particular catchment is its wide variety of surface conditions, ranging from flat, semi-arid areas in the west (mainly used for dryland farming) to the alpine ranges in the east near Canberra. Moreover, the seasonal differences and sporadic rain events during the campaigns meant that a wide range of conditions were found, resulting in a data set ranging from hot and dry to wet and cold. A total of $50,000 \mathrm{~km}^{2}$ was covered, using an airborne sensor platform, operating over the same microwave wavelength as SMOS.
\end{abstract}

The data collected with the airborne platform included passive L-band microwave observations, as well as measurements in the thermal infrared and eight spectral bands. Moreover, the catchment contains over 60 permanent soil moisture monitoring stations which were supplemented by spatially high-resolution soil moisture measurements across 20 focus farms on selected overpass days.

In this paper, we discuss the quality of both brightness temperature data sets, as well as compare the ground station data against the SMOS Level 2 soil moisture product. It is found that the overall brightness temperature observations of SMOS tend to be systematically $\sim 10 \mathrm{~K}$ warmer than the airborne observations, both during the winter and summer periods, as well as across different vegetation types, which suggests that there is a persistent bias in one of the data sets. Similarly, the SMOS soil moisture products consistently underestimate the soil moisture observed on the ground. Nevertheless, a significant improvement in the accuracy of the soil moisture product has been achieved between the latest two Level 2 versions and it is expected that the accuracy will again increase when the data from all validation campaigns have been assessed.

Keywords: passive microwave remote sensing, soil moisture, ground validation 
Rüdiger et al., Validation of the Level 1c and Level 2 SMOS Products with Airborne and Ground-based Observations

\section{INTRODUCTION}

Soil moisture is one of the most important environmental states, regulating the water and energy exchange between the atmosphere and the land surface, influencing the infiltration rate of precipitation and river runon and therefore is a key factor in floods and their extent. Moreover, traditional agricultural practices rely on root zone soil moisture to adequately manage irrigation applications and also sowing and harvesting timing. In a climatic context, soil moisture is used as an indicator for droughts and their length and impact. Because of its key role in all these aspects, soil moisture was named as one of 50 Essential Climate Variables (ECV) by the Global Climate Observing System (GCOS) (WMO, 2010). GCOS is an initiative led by a number of organisation, such as the World Meteorological Organization (WMO), United Nations Educational Scientific and Cultural Organization (UNESCO), and the International Council for Science (ICSU), among others.

With the recognition of the global role of soil moisture, both the European Space Agency (ESA) and the National Aeronautics and Space Administration (NASA) decided on spaceborne missions dedicated to the observation of soil moisture. The first of these missions is the ESA-led Soil Moisture and Ocean Salinity (SMOS) satellite (Kerr et al., 2010), which was launched on 2 November 2009. It will be followed by the ESA Sentinel-1 mission in 2012 and the Soil Moisture Active Passive (SMAP) mission in 2015 (Entekhabi et al., 2010). Both SMOS and SMAP are and will be operating at L-band ( 1.4GHz), which was found to be the optimal frequency for soil moisture observations, due to the limited interference or attenuation by vegetation and atmosphere. A further mission, NASA's Aquarius (Levine et al., 2007), was launched in June 2011 and also includes similar capabilities as SMOS and SMAP, however it was designed principally for ocean salinity monitoring and therefore has a significantly lower spatial resolution than SMOS and SMAP.

The use of L-band as a means of observing land surface states has only once been attempted during the 19734 Skylab mission (Eagleman and Lin, 1976). However, few observations are still available (Drusch et al., 2009), making the development of reliable calibration parameters and retrieval algorithms difficult. Additionally, SMOS has been designed as a 2-dimensional interferometric radiometer, which makes it the first earth observation satellite designed in this way, requiring extensive validation and calibration efforts. The Australian Airborne Cal/val Experiments for SMOS (AACES [www.moisturemap.monash.edu.au/aaces]; Peischl et al., 2009) represented the Australian contributions to the calibration and validation. Those campaigns were undertaken during the Australian summer (January/February 2010) and winter (September 2010) throughout the Murrumbidgee River catchment in south-eastern Australia. The data collected during those campaigns include airborne observations at L-band and eight different spectral bands at $1 \mathrm{~km}$ resolution, which were complemented with high-resolution groundbased soil moisture and vegetation measurements at selected focus farms across the entire catchment.

In this paper, we compare at first the brightness temperature observations obtained from the satellite and the aircraft in order to assess any differences between expected and acquired spaceborne observations. Following this assessment, the actual soil moisture retrieval from SMOS is compared with the in-situ observations. All comparisons are undertaken using the recently reprocessed SMOS Level 1c brightness temperatures (v.3.46) and Level 2 soil moisture products (v.4.0).

\section{STUDY AREA AND DATASETS}

\subsection{Murrumbidgee River Catchment}

The Murrumbidgee River catchment is located in south-eastern Australia between $33-37^{\circ}$ southern latitude and $143-150^{\circ}$ eastern longitude (Fig. 1) and encompasses a total area of $82,000 \mathrm{~km}^{2}$. It is a subcatchment of the Murray-Darling basin and includes a wide variety of surface and climatological conditions, making it the ideal testbed for large scale airborne validation campaigns for satellite missions. The eastern part of the catchment is located within the Snowy Mountains and also includes Canberra in the far east. While the eastern part is dominated by a high level of relief, particularly in the south-east, the central and western parts of the catchment are relatively flat. The vegetation and climatic conditions vary according to topography. In summer, the areas in the west and east are generally relatively dry and hot and are mainly used for extensive dry-land farming, with the exemption of the centrally located Coleambally Irrigation Area. The winters are cold throughout. The average annual precipitation ranges from $\sim 500 \mathrm{~mm}$ in the west to $2000 \mathrm{~mm}$ in the east. The vegetation generally consists of sparse grasslands in the west, agricultural fields in the central irrigated areas, and denser grasslands and forests in the eastern pre-alpine areas. There are only two notable urban centres in the catchment (Canberra and Wagga Wagga), while all other towns are negligible from a radiometric point of view. 
Rüdiger et al., Validation of the Level 1c and Level 2 SMOS Products with Airborne and Ground-based Observations

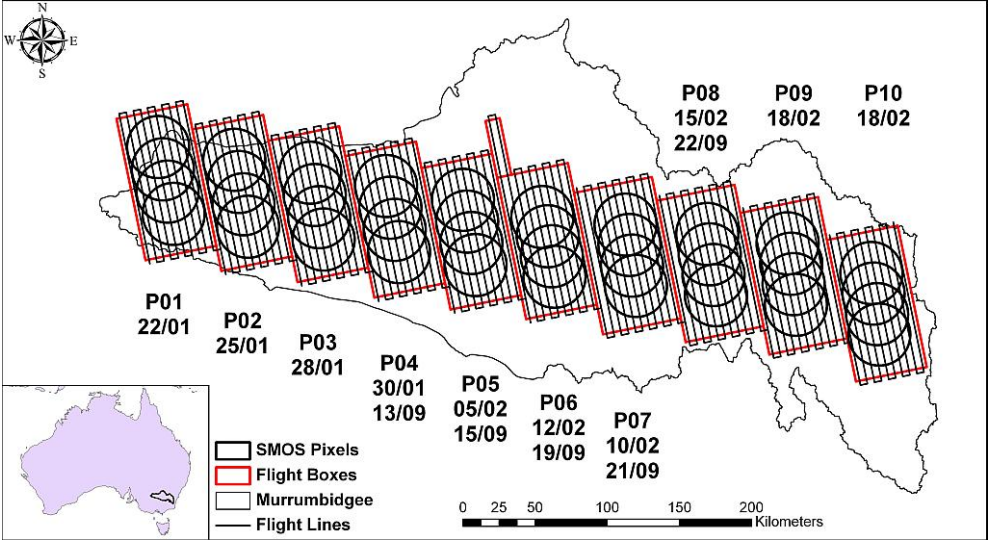

Figure 1. Location of the Murrumbidgee River catchment within Australia (inset), flight domains (red; with dates of flight coverage) with flight lines (black lines), and full SMOS pixels within the flight domains (balck circles).

\subsection{Airborne and Ground- based Observations}

The airborne data set consists of both passive microwave and multi-spectral observations, generally collected at a resolution of $1 \mathrm{~km}$ from a flying altitude of $\sim 3000 \mathrm{~m}$ above ground level (a.g.l.). Additional data were collected at lower altitudes $(150 \mathrm{~m}$ a.g.1.), however they were spatially limited and will not be considered in this study. The microwave emissions were observed using the Polarimetric Lband Multi-beam Radiometer (PLMR; Panciera et al., 2008), operating at a frequency of $1.413 \mathrm{GHz}( \pm 24 \mathrm{MHz})$ and with

antenna observation angles of $\pm 7^{\circ}, \pm 21.5^{\circ}$ and $\pm 38.5^{\circ}$, which reproduce the multi-angular capabilities of SMOS (see next section). The accuracy of PLMR has been determined to be better than $2 \mathrm{~K}$ (Panciera et al., 2008). The instrument was flown in push-broom configuration to allow the largest swath coverage possible (Peischl et al., 2009), resulting in a $6 \mathrm{~km}$ wide swath, providing data at various incidence angles. The area covered on each day included a domain of $50 \times 100 \mathrm{~km}$, which was designed specifically to include four entire SMOS footprints. Moreover, the flights were undertaken on the same days as SMOS overpasses occurred. While the SMOS data acquisition is instantaneous, PLMR flights lasted on average 5 hours. To correct for any changes in the effective surface temperatures, the PLMR data were corrected to a reference soil temperature at 6am of the day of acquisition. This technique is based on Jackson (2001) and is described in more detail in Rüdiger et al. (2011).

The aircraft data were complemented by a ground-based data collection. For that purpose, 20 representative focus farms (two for each flight domain) were identified, throughout which the soil moisture and temperature, as well as vegetation measurements were taken. The soil moisture measurements and temperature measurements consist of data collected at temporarily installed stations, capturing the diurnal cycle during the data acquisition, and also roaming soil moisture measurements with hand held instruments (HDAS; Panciera et al., 2008). The roaming soil moisture and temperature data were acquired along six $5 \mathrm{~km}$ long transects, with three measurements taken every $50 \mathrm{~m}$, providing a sufficiently dense observation base to determine the spatial variability throughout the catchment.

The AACES campaigns are described in detail in Peischl et al. (2009) and on a dedicated website (http://www.moisturemap.monash.edu.au/aaces).

\subsection{Soil Moisture and Ocean Salinity (SMOS) satellite}

As mentioned previously, the design of SMOS is similar to a 2-dimensional interferometric radiometer. It consists of 69 sensors regularly distributed on a Y-shaped structure. The satellite design along with its tilt angle of $32.5^{\circ}$ result in the acquisition of data at incidence angles of $-10^{\circ}$ to $60^{\circ}$ (Kerr et al., 2010). The full swath width is $\sim 1000 \mathrm{~km}$, with individual footprints being in the order of $43 \mathrm{~km}$ on average. The satellite orbits at an altitude of $750 \mathrm{~km}$ and its overpass time is at $6 \mathrm{am}$ and $6 \mathrm{pm}$, with a repeat cycle of approximately 3 days at the equator (higher frequencies are achieved closer to the poles). Currently, data are available at Level 1 (brightness temperatures) and Level 2 (Soil Moisture and Ocean Salinity). In this study the Level 1c brightness temperature and Level 2 soil moisture products are being used. Both data products are the (at the time of writing) current reprocessed data set (L1c: v.3.46; L2: v.4.0). Both data sets are provided on a regular equal area geolocated grid (Icosahedral Snyder Equal Area - ISEA 4H9) with a data spacing of $15 \mathrm{~km}$ over land. The Level 2 soil moisture product is derived with a radiative transfer model based on the L-band Microwave Emission Model for the Biosphere (L-MEB; Wigneron et al., 2007). Due to its design, SMOS provides data across a large range of incidence angles for the same point in space and time. The number of observations near nadir may be in excess of 200, with a reduced number toward the edges of the swath. Fig. 2 shows the example of brightness temperatures acquired over the Murrumbidgee River catchment on 14 
Rüdiger et al., Validation of the Level 1c and Level 2 SMOS Products with Airborne and Ground-based Observations
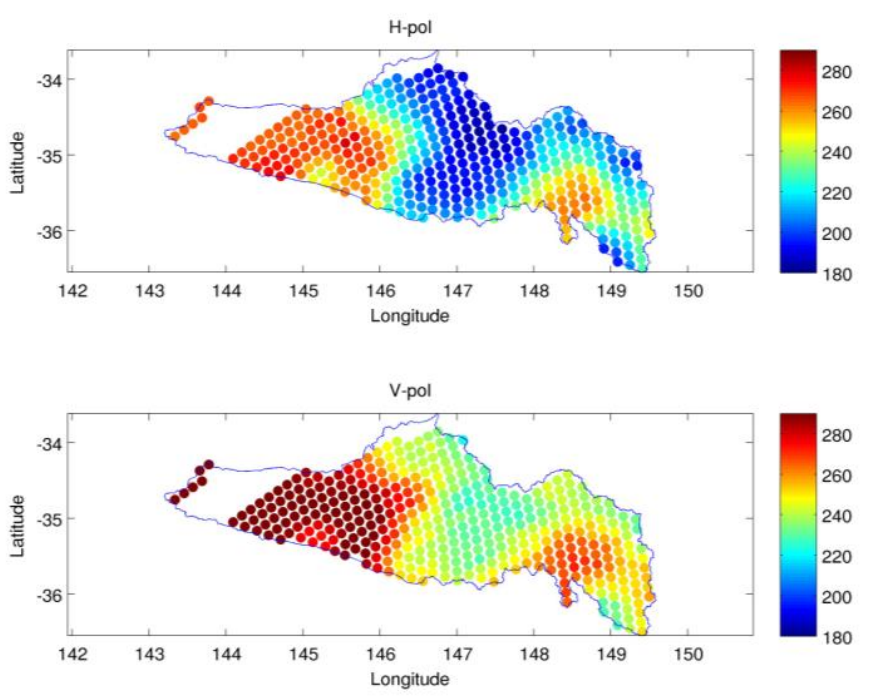

Figure 2. Example of SMOS brightness temperatures (incidence angle: $38^{\circ}$ ) acquired on $14 \mathrm{Feb} 2010$ over the Murrumbidgee River catchment.
February 2010 (ascending orbit), showing a clear pattern after the significant storm events over the previous two days.

\section{RESULTS}

\subsection{Brightness Temperature Products}

To avoid data contamination from sun glint, alias effects, and radio-frequency interference (RFI), the data flags of SMOS were used to filter those affected data points. To facilitate the sun glint effect, only data from the ascending (morning) overpasses were considered, of those only data not containing anomalous artefacts from the image reconstruction were passed into the processing software. As Australia is generally free of RFI, none was detected, apart from a number of locations around

Canberra. While the effect of those localised RFI sources was spatially confined to a few pixels in the PLMR data, it would not affect the averaging of PLMR data across a whole SMOS footprint. However, SMOS data obtained over and near Canberra displayed significant anomalies. Consequently, data from this area are not included in the final analysis.

Fig. 3 displays the comparison of SMOS and PLMR data for a day of the AACES summer campaign. An offset is clearly visible over the entire range of incidence angles. Assuming PLMR as a true reference, it was found that SMOS consistently overestimated the airborne data by $\sim 11 \mathrm{~K}$ on average (with some variation between the different incidence angles), while the better result is seen in the vertically polarized data (Fig. 4). It was found for both polarizations and the observed incidence angles that the RMSE ranged from 10-13K with biases from $8-12 \mathrm{~K}$. While the RMSEs are large, it is clear that most is due to the persistent warm bias in the SMOS data. When this bias is removed, both polarizations will be closer to the design accuracy of SMOS of $4 \mathrm{~K}$. Figure 4 shows the scatter plot of SMOS and PLMR data. It clearly shows the persistent difference between the two data sets. However, most observations are within the first standard deviation of the observed PLMR mean brightness temperature, which suggests a statistically significant relationship.

In order to validate the initial assumption that PLMR may be used as a true reference, L-MEB with its standard parameters and the observed vegetation water content was used to estimate the local brightness temperatures (not shown). It was found that there is a very good agreement between model predictions and airborne observations for dry conditions, though a discrepancy is obvious for colder/wetter conditions. This is mainly due to a significantly increased vegetation water content which L-MEB interprets as denser vegetation, but which in reality was likely due to the observed water on the vegetation due to

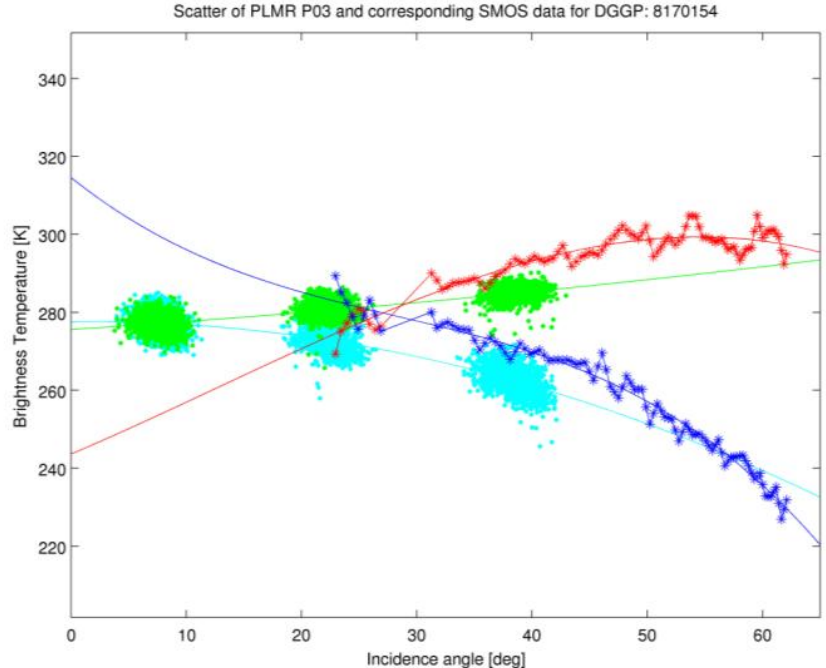

Figure 3. Multi-angular data of a SMOS acquisition (v-pol red; h-pol - blue) along with the corresponding PLMR data (vpol - green; h-pol - magenta). 
Rüdiger et al., Validation of the Level 1c and Level 2 SMOS Products with Airborne and Ground-based Observations
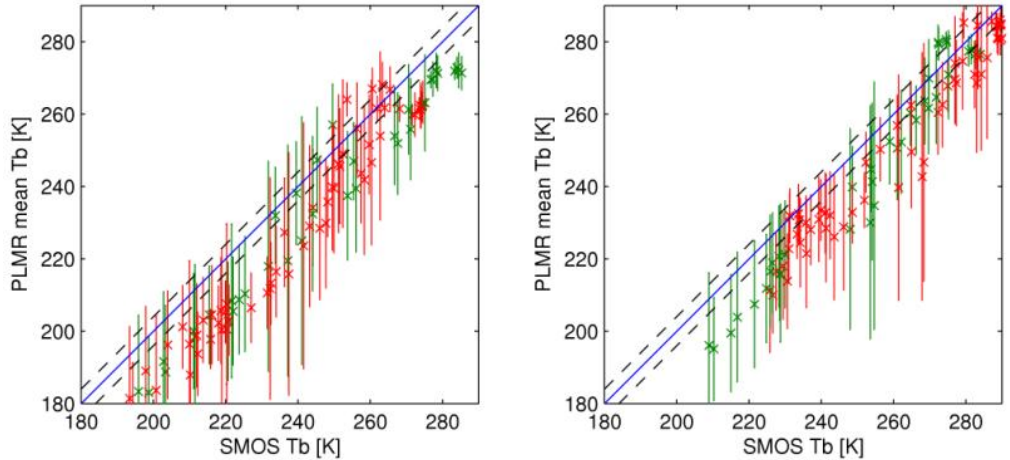

Figure 4. Scatterplots of the comparison of SMOS and PLMR data (vpol and h-pol) for both AACES campaigns (summer -red, winter green). The errorbars indicate the standard deviation of PLMR data within the corresponding SMOS footprint, and the dashed line the design accuracy of SMOS (4K). dew and precipitation (however, this aspect was not taken into consideration for the purpose of this paper). This leads L-MEB to overestimate the vegetation opacity and therefore its contribution to the microwave emissions. This may pose a problem for future assessments, and shall be covered in a more detailed study.

\subsection{Soil Moisture Products}

An example of the spatial variability of soil moisture as observed by SMOS is shown in Fig. 5a. This pattern is in agreement with the precipitation

patterns observed during this period of the field campaign and is also well aligned with the corresponding brightness temperature observations (Fig. 2). The validation of the soil moisture products was undertaken by comparison with the high resolution soil moisture observations collected during the respective sampling days. The initial very dry conditions $\left(\sim 0.03 \mathrm{~m}^{3} \mathrm{~m}^{-3}\right)$ in the western part of the Murrumbidgee River catchment caused significant retrieval problems, as the algorithm of the radiative transfer model cannot converge to a useful solution under such conditions. Moreover, this is even less than the design accuracy of SMOS. Therefore, the analysis excluded those days on which the retrieval could not be performed for the areas. While the in-situ soil moisture stations do not cover the entire SMOS footprint, the comparison allows estimating the spatial variability across the area, assuming that soil moisture collected across a $10 \mathrm{~km}^{2}$ area can be taken as a representative reference.

Fig. 5b displays the correlation of the two data sets. It is evident that there is a persistent bias between SMOS and the ground-based measurements, with the exception of four sites. The overall bias is in the order of 0.12 $\mathrm{m}^{3} \mathrm{~m}^{-3}$, which is mainly driven by the significant dry bias during the winter period. Removing the bias determined for the summer and winter campaigns, the RMSEs are reduced to $0.09 \mathrm{~m}^{3} \mathrm{~m}^{-3}$ for the summer, and $0.05 \mathrm{~m}^{3} \mathrm{~m}^{-3}$ for the winter. The very dry bias in the summer data is due to data collected two days after intensive precipitation events (in excess of $150 \mathrm{~mm}$ over two days).
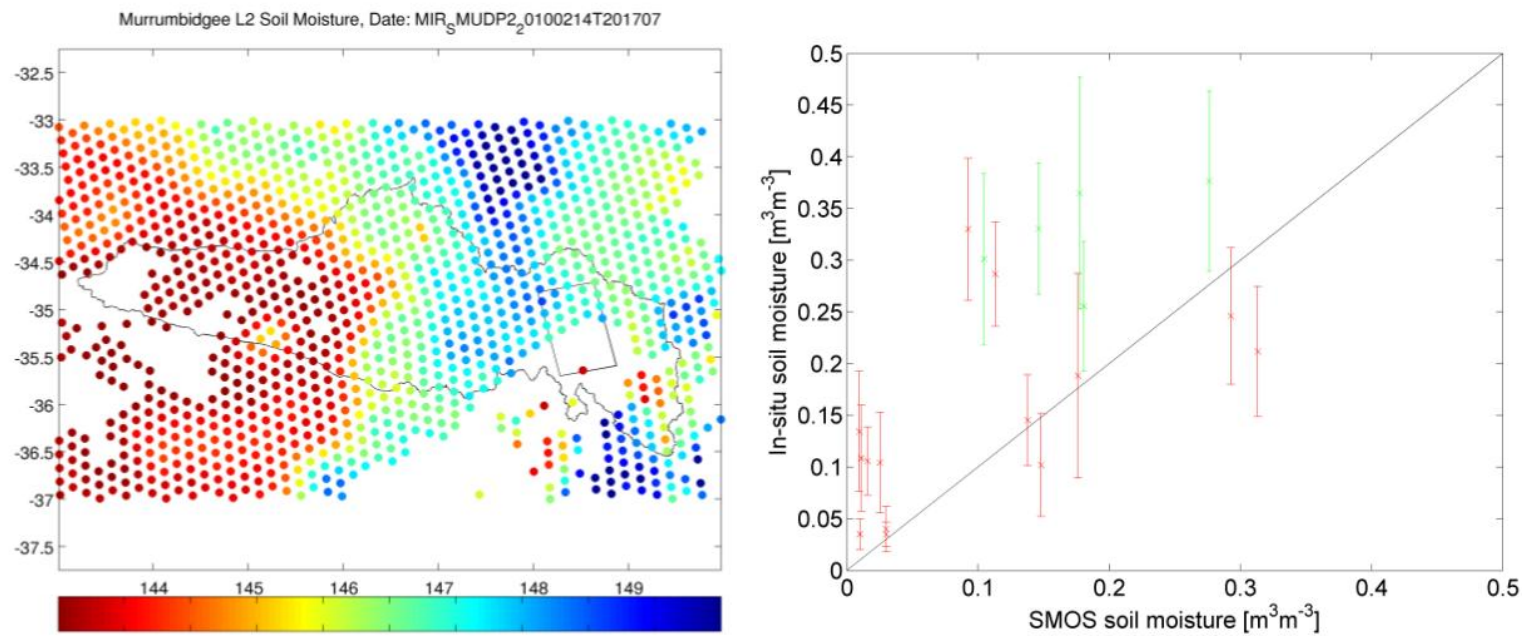

Figure 5. a) Soil Moisture data retrieved from SMOS on 14 February 2010 (see also Fig. 2 for the corresponding brightness temperatures) and b) scatter of ground-based and SMOS soil moisture data (summer -red, winter - green). The error bars indicate the standard deviation of the in-situ soil moisture within a particular focus farm. 
Rüdiger et al., Validation of the Level 1c and Level 2 SMOS Products with Airborne and Ground-based Observations

\section{DISCUSSION}

The results presented here show a promising development of SMOS. While the bias-corrected RMSE values of the soil moisture appear to be relatively high, it has to be noted that after removing the anomalous data from days following intensive precipitation events would lead to a significant improvement. Some outstanding issues still have to be covered, e.g. the source of the persistent bias in the brightness temperature and soil moisture data. However, those two aspects are interrelated. Sensitivity studies have shown that $10 \mathrm{~K}$ bias in the brightness temperature estimations may lead to a $0.05-0.06 \mathrm{~m}^{3} \mathrm{~m}^{-3}$ bias in the soil moisture retrieval for herbaceous vegetation types (Rüdiger et al,. 2011). Given that biases of these magnitudes are found in the presented data, the removal of the bias within the brightness temperature data set would ultimately reduce the error in the soil moisture data below the design accuracy of SMOS.

Further analyses of the data are needed to identify why SMOS displays such significant differences when compared to airborne and ground-based observations. Some of the questions to be answered here is the apparent bias introduced in the presence of water on vegetation. Furthermore, a large scale comparison of soil moisture information obtained from the airborne data should provide additional information on the spatial heterogeneity or variability of the soil moisture within a SMOS footprint. This will also allow to study in more detail the influence of different vegetation types within such an area.

\section{CONCLUSIONS}

This paper presented the validation of SMOS Level 1c brightness temperature and Level 2 soil moisture products, using airborne and ground-based observations of the Australian Airborne Cal/val Experiments for SMOS (AACES) undertaken in the Austral winter and summer periods of 2010. It is shown that SMOS L1c data appear to have a warm bias of approximately $11 \mathrm{~K}$ when compared to the airborne observations. When removing this bias, the SMOS observations are close to the satellite's design accuracy. Similarly, the soil moisture suffers from a dry bias when compared to ground observations. Some of the dry bias in the soil moisture may be explained with some of the bias observed in the brightness temperature, as a warm bias is tantamount of drier conditions than expected. As this dry bias persists during both the summer and winter periods, it may be assumed as a constant feature and further research will have to show whether this is due to the airborne and satellite data.

When compared to the accuracy of other satellite missions (Draper et al., 2009; Rüdiger et al., 2009), SMOS appears to perform with less accuracy. To counter this argument, it has to be said that the calibration and validation campaigns for SMOS around the globe are still ongoing and that the first results of just over one year of data, while not perfect, are very promising. With future corrections to the calibration and retrieval algorithm parameters, SMOS should indeed achieve the accuracy it was designed for.

\section{ACKNOWLEDGMENTS}

This project is funded by an Australian Research Council Discovery Project (DP0879212). The authors would like to thank all participants, institutes and local landholders of both AACES campaigns for volunteering time, resources, and land access to this project.

\section{REFERENCES}

Draper, C.S., Walker, J.P., Steinle, P.J., de Jeu, R.A.M. and Holmes, T.R.H. (2009). An Evaluation of AMSR-E Derived Soil Moisture Over Australia. Remote Sensing of Environment, 113, 703-710, doi:10.1016/j.rse.2008.11.011.

Drusch, M., Holmes, T., de Rosnay, P. and Balsamo, G. (2009). Comparing ERA-40-based L-band brightness temperatures with Skylab observations: A calibration/validation study using the community microwave emission model. Journal of Hydrometeorology, 10, 213-226, doi: 10.1175/2008JHM964.1.

Eagleman, J.R.. and Lin, W.C. (1976). Remote sensing of soil moisture by a 21-cm passive radiotmeter. Journal of Geophyical. Research, 81, 3660-3666.

Entekhabi, D. Njoku, E.G., O’Neill, P.E., Kellogg, K.H., Crow, W.T., Edelstein, W.N., Entin, J.K., Goodman, S.D., Jackson, T.J., Johnson, J., Kimball, J., Piepmeier, J.R., Koster, R.D., Martin, N., McDonald, K.C., Moghaddam, M., Moran, S., Reichle, R., Shi, J.C., Spencer, M.W., Thurman, S.W., Tsang, L. and Van Zyl, 
Rüdiger et al., Validation of the Level 1c and Level 2 SMOS Products with Airborne and Ground-based Observations

J. (2010). The Soil Moisture Active Passive (SMAP) mission. Proceeding of the IEEE, 98(5), 704-716, doi:10.1109/JPROC.2010.2043918.

Jackson, T.J. (2001). Multiple Resolution Analysis of L-Band Brightness Temperature for Soil Moisture. IEEE Transactions on Geoscience and Remote Sensing, 39(1), 151-164, doi: 10.1109/36.898677.

Kerr, Y., Waldteufel, P., Wigneron, J.-P., Delwart, S., Cabot, F., Boutin, J., Escorihuela, M.J., Font, J., Reul, N. and Gruhier, C. (2010). The SMOS Mission: New Tool for Monitoring Key Elements of the Global Water Cycle. Proceedings of the IEEE, 98(5), 666-687, doi:10.1109/JPROC.2010.2043032.

Le Vine, D.M., Lagerloef, G.S.E., Colomb, F.R., Yueh, S.H. and Pellerano, F.A. (2007). Aquarius: an instrument to monitor sea surface salinity from space. IEEE Transactions on Geoscience and. Remote Sensing, 45(7), 2040-2050, doi:10.1109/TGRS.2007.898092.

Panciera, R., Walker, J.P., Kalma, J.D., Kim, E.J., Hacker, J., Merlin, O. and Berger, M. (2008). The NAFE'05/CoSMOS Dataset: Towards SMOS Soil Moisture Retrieval, Downscaling and Assimilation. IEEE Transactions on Geoscience and. Remote Sensing, 46(3), 736-745, doi:10.1109/TGRS.2007.915403.

Peischl, S., Walker, J.P., Allahmoradi, M., Barrett, D., Gurney, R., Kerr, Y., Kim, E., Le Marshall, J., Rüdiger, C., Ryu, D. and Ye, N. (2009). Towards Validation of SMOS Using Airborne and Ground Data over the Murrumbidgee Catchment. In: R.S. Anderssen, R.D. Braddock, and L.T.H. Newham (Eds.), Proceedings of the International Congress on Modelling and Simulation (MODSIM). Modelling and Simulation Society of Australia and New Zealand, Inc., Cairns, Australia, 13-17 July, 2009, 3733-3739.

Rüdiger, C., Calvet, J.-C., Gruhier, C., Holmes, T.R.H., de Jeu,, R.A.M. and Wagner, W. (2009). An Intercomparison of ERS-Scat and AMSR-E Observations, and Soil Moisture Simulations over France. Journal of Hydrometeorology, 10(2), 431-447, doi:10.1175/2008JHM997.1.

Rüdiger, C., Walker, J.P. and Kerr, Y.H. (2011). On the airborne spatial coverage requirement for microwave satellite validation. Geoscience and Remote Sensing Letters, 8(4), 824-828, doi: 10.1109/LGRS.2011.2116766

Wigneron, J.-P., Kerr, Y., Waldteufel, P., Saleh, K., Escorihuela, M.J., Richaume, P., Ferrazzoli, P., de Rosnay, P., Gurney, R., Calvet, J.-C., Grant, J.P., Guglielmetti, M., Hornbuckle, B., Matzler, C., Pellarin, T. and Schwank, M. (2007). L-band microwave emission of the biosphere (L-MEB) model: Description and calibration against experimental data sets over crop fields. Remote Sensing of the Environment., 107, 639-655.

World Meteorological Organization, 2010. Implementation Plan for the Global Observing System for Climate in Support of the UNFCCC (2010 Update), GCOS-138, 186p., August 2010, Geneva, Switzerland. 